\title{
The Predictive Role of NEDA in the Long-Term Course of Multiple Sclerosis
}

\author{
NEDA'nın Multipl Sklerozun Uzun Dönem Seyri Üzerindeki Belirleyici Etkisi
}

\section{The Predictive Role of NEDA in the Long-Term Course of Multiple Sclerosis}

Many important developments have occurred in the treatment of multiple sclerosis (MS) in the last two decades. The long-term effects of treatments, except-disease modifying agents such as interferon and glatiramer, are not clear. Studies about the natural course of disease performed during the pretreatment era showed that approximately half of patients transform to progressive stage in 15 years. The amount of disease-course modifying effects of current treatments is not clear. A cohort study by researchers from the University of California in San Francisco (UCSF) tried to answer this question (1). This was a long-term follow-up study of patients with MS who were under treatment. The study included 517 patients who were being followed up in the MS clinic of UCSF beginning from 2004. The patients were classified into two groups as relapsing MS (RMS) and progressive MS (PMS), and were followed up for 10 years. During this period, Extended Disability Status Scale (EDSS), PASAT-3 for cognitive evaluation, 9-hole peg test for manual dexterity, and the Timed 25 Foot Walk (25-FW) test for leg function were performed regularly and recorded.

In this study, the term No Evidence of Disease Activity (NEDA), which has been used more commonly during the last 5 years, was also used. NEDA can be summarized as a state in which no radiologic or clinical activity is present. The researchers examined long-term disease activities of patients who fulfilled criteria for NEDA in the second year of the study. One of the striking points of the study was the prognosis of these patients. Interestingly, Cree et al. (1) found that NEDA was not a good predictor as expected, although another study detected better EDSS scores in patients with NEDA (2).

Ten percent of patients with RMS transformed to secondary progressive phase during 10-year follow-up period. After 17 years from initiation of disease, $11 \%$ of patients had an EDSS score $\geq 6$, and $18 \%$ transformed to secondary progressive MS from RMS. Assessment of transformation risk according to sex and age showed that female sex decreases the risk, whereas higher age increases it.

Moreover, 25-OH vitamin D level was also assessed and its effect on disease course was evaluated, but no association was found with long-term disease activity.

No difference was found between disease courses of patients who received second-order treatments (natalizumab, rituximab, cyclophosphamide), because they were believed to have been transformed into secondary progression and patients who used disease-modifying treatments. Another important finding of this study was the lower rate of EDSS worsening in patients with RMS with current treatments, and the appearance of this worsening later than previous studies. As a last word, unlike other studies, NEDA was not found a significant predictor of prognosis or disease worsening (1).

Address for Correspondence/Yazışma Adresi: Özgü Kizek MD, İstanbul University İstanbul Faculty of Medicine, Department of Neurology, İstanbul, Turkey Phone: +90 5372899463 E-mail: ozgukizek@gmail.com

Received/Geliş Tarihi: 18.12.2016 Accepted/Kabul Tarihi: 18.12.2016

${ }^{\circ}$ Copyright 2017 by Turkish Neurological Society

Turkish Journal of Neurology published by Galenos Publishing House. 


\section{References}

1. University of California, San Francisco MS-EPIC Team: Cree BA, Gourraud PA, Oksenberg JR, Bevan C, Crabtree-Hartman E, Gelfand JM, Goodin DS, Graves J, Green AJ, Mowry E, Okuda DT, Pelletier D, von Büdingen HC, Zamvil SS, Agrawal A, Caillier S, Ciocca C, Gomez R, Kanner R, Lincoln R,
Lizee A, Qualley P, Santaniello A, Suleiman L, Bucci M, Panara V, Papinutto N, Stern WA, Zhu AH, Cutter GR, Baranzini S, Henry RG, Hauser SL. Long-term evolution of multiple sclerosis disability in the treatment era. Ann Neurol 2016;80:499-510.

2. Rotstein DL, Healy BC, Malik MT, Chitnis T, Weiner HL. Evaluation of no evidence of disease activity in a 7-year longitudinal multiple sclerosis cohort. JAMA Neurol 2015;72:152-158. 